\title{
Green and Safety School Regional Program to Sustainable Development Using Limited Traffic Zone
}

\author{
Francesco Russo $^{1 *}$, Tommaso Calabrò ${ }^{2}$, Giuseppe Iiritano ${ }^{2}$, Domenica Savia Pellicanò ${ }^{1}$, Giovanna Petrungaro ${ }^{2}$, \\ Maria Rosaria Trecozzi \\ ${ }^{1}$ Dipartimento di Ingegneria dell'Informazione, delle Infrastrutture e dell'Energia Sostenibile, Università degli Studi \\ Mediterranea, Reggio Calabria 89124, Italy \\ ${ }^{2}$ Dipartimento Lavori Pubblici, Public Administration of Regione Calabria, Catanzaro 88100, Italy
}

Corresponding Author Email: francesco.russo@unirc.it

https://doi.org/10.18280/ijsdp.160107

Received: 19 September 2020

Accepted: 2 December 2020

\section{Keywords:}

transportation planning, sustainable development, urban planning, sustainable mobility, pedestrian area, social distance, risk reduction, limited traffic zone

\begin{abstract}
The traffic around the schools is one of the worst events for sustainability. The effects are heavy for pollution, for safety deriving from multiplied walk-car cross, for autonomy reduced for student. This paper discusses on Green and Safety School program that realizes Limited Traffic Zones (LTZ) around the schools. Calabria Region has made political and technical decisions oriented towards sustainable development, according to international, European and national targets: by Regional Transportation Plan (RTP), the Region has implemented several ways for realization of the planned measures relative to the urban centres defined by Action 2 Urban areas; by School Plan and program the Region has invested to reduce the vulnerability of school building. The aim of Green and Safety School program is offering a new and never developed field for social, economic and environmental sustainability in urban areas and to propose a strategy for traffic control near schools from basic considerations regarding a problem common of all cities around the world. This program derives from the results obtained with two different previously implemented programs: one relative to the rebuild of school who reduce risk (Scuola Sicura) and another one to the City logistics (leaving from RTP). From an advanced synthesis of these 2 programs born the very new use of LTZ. Green and Safety School is oriented to guarantee green areas and to reduce risk outside school. Even if the program leaves before COVID-19, it assumes significant importance to guarantee social distancing.
\end{abstract}

\section{INTRODUCTION}

The components of sustainable development are environment, economy and society [1].

In urban areas, the three components are strongly interconnected and bring out significant effects on citizens.

Leaving from a general statement regarding sustainable development, the international documents set global goals without introducing executive ways to the administrations of local levels. Then, it's crucial to highlight the possibility of built a clear connection from the goals defined by top international organizations, as UN, to the final implementation programs adopted by a marginal region, as Calabria, passing along UE and Italian strategy.

In 2015, UN Member States adopted 17 Sustainable Development Goals (SDGs) and 169 targets to achieve by $2030[2,3]$. They proposed an action plan to end poverty, to protect the planet and to improve the lives and prospects of everyone in the world.

In the same year, the members of the Framework Convention on Climate Change (UNFCCC) signed the Paris Agreement to contain terrestrial heating well below $2^{\circ} \mathrm{C}$, compared to pre-industrial levels, by significantly reducing $\mathrm{CO}_{2}$ emissions against climate change [4].
In 2019, the European Commission considered the environmental sustainability as the basis of programming for 2021-2027 Regional Operational Program [5].

In 2017, Italy developed a strategy to achieve the sustainable development proposed by the 2030 Agenda [6]

In 2016, Calabria Region made sustainable development the central theme of its main planning documents: The Economy and Finance Document 2019-2021 (EFDR) [7] and the Regional Transportation Plan (RTP) [8]. Calabria stipulated a specific agreement with the Ministry of the Environment and the Protection of the Territory and the Sea (MATTM) to align its strategy with the international, European and national one. In Figure 1 is presented the location of Calabria territory in the context of Italy [9]. Calabria is a region in the Southern Italy, the southern most of continental Europe, with about 2 millions of inhabitants and one of the lowest GDP per capita in the EU. In the last 20 years, the Calabria has been in a situation of economic under development and of delay in production and industrial capacity; a region behind in comparison not only with the European countries but also with other regions of Southern Italy.

The Region has carried different activities for sustainable development with City logistics [10, 11], Scuola Sicura [12] and Green and Safety School programs related to urban areas. 


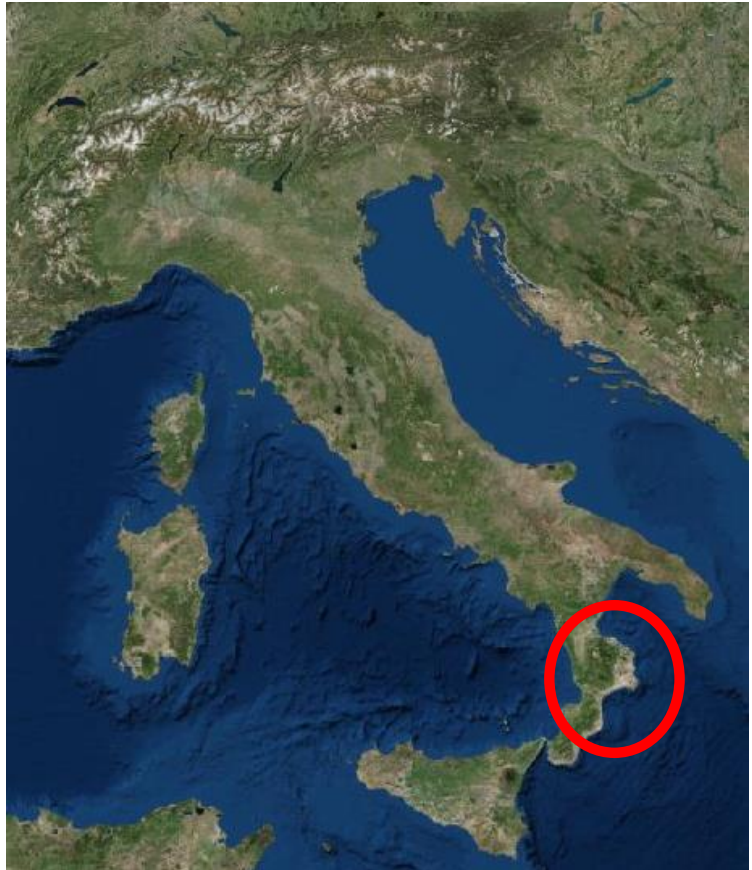

Figure 1. Calabria (Elaboration from [9])

These programs don't born as a rabbit from the hat, but have as background the international and national goals before summarized. The international and national plans are generalist and lack of specific indications. The activities promoted by regional programs are executives ways that translate the theoretical goals regarding Sustainable Development in empirical facts, that impact on the territory and on people's real life.

They are part of a general framework of sustainable development including activities about the touristic ports and the Magna Grecian and the Parks cycle routes [13]. The goal of sustainability and specific programs were strongly developed in the 2015-2020 period by the regional government directed by Mario Oliverio.

City logistics program [14] refers to interventions that can be implemented for urban logistics to Achieve essentially $\mathrm{CO}_{2-}$ free city logistics in major urban centres by 2030 [15].

Scuola Sicura program refers to interventions in schools considering seismic "heavy" improvement, giving priority to adjustment/demolition/reconstruction [12].

Green and Safety School program refers to mobility around the schools. The aim is to realize green and safety accessibility to students' and staff schools according to the indications of Law n. 285 of 1997 [16], in line with the sustainability targets at international, European, national and regional level, and consistent with the strategies of City Logistics (that is an emblematic measure of RTP) and Scuola Sicura programs too. In fact, Green and Safety School creates a zone where the two programs City Logistics and Scuola Sicura are overlapped and/or can have a cut; then, this new program extends the effect of the two previous separated programs in a new type of Limited Traffic Zone (LTZ) [17], never used in a large regional program.

In Italy, several initiatives refer to school mobility to improve accessibility, and road safety specially.

Camina is a project developed some years ago in Emilia Romagna Region, aiming to make the cities friends of children and adolescents.

Camina provides work tools for all those who deal with cities and childhood. I Quaderni di Camina suggest strategies, tools and actions for the mobility of children and adolescents. Some interventions concern, for example, design of homeschool safe paths [18] or integrated policies to reduce accidents in the city and achieve greater safety on the roads and to develop environmentally and socially sustainable mobility $[19,20]$, experiences of participatory planning and design of public areas $[21,22]$.

The Non-Profit Organizations Cittadinanzattiva and Save the Children are the promoters of an Italian law proposal on risk reduction in school buildings after the numerous structural collapses that occurred, also due to earthquakes, which caused victims. This proposal is based on a 9-point manifesto: The right of children, teachers and non-teaching staff to school safety; (...); The social participation in school safety; (...); The culture of prevention as a training objective; The support for children and adolescents involved in emergencies [23].

The main question that emerges from the reported elements is how build a plan and then specific public programs that can implement the sustainability target in the urban areas merging global goals and local realizations. Different plans and programs have been implemented to realize executive ways by Calabria Region. There are two specific macro activities that constitute the background knowledge of Green and Safety School: the first is the Regional Transportation Plan; the second is the School Plan and its direct implementation program Scuola Sicura. The results obtained with the two macro activities and the accumulation of knowledge and expertize suggest to push ahead a new executive way. Then, the main problem studied in the paper is the long bridge with more spans between international very impressive goals and disclaimer programs that impact on real life. The problem is how to merge different advanced programs that produce notable results, in a most advanced new one where tries to reduce risk for natural events and for car accidents, using LTZ.

In this paper, the strategies to pursue sustainability target in urban areas, to implement the Regional Transportation Plan and to develop Scuola Sicura program are reported in section 2. Therefore, in section 3 Green and Safety School program with interventions is described, as discussed with no-profit organizations, citizens, researchers and technicians.

Green and Safety School program is the first one planned by a regional government, after discussion with social parts and researchers, that pushes the cities to be more virtuous introducing a new type of LTZ. It is an innovative and educational program for local administrations which, engaged as they are in more urgent and immediate problems, often overlook these aspects.

The novelty of this paper is to provide a new and never developed field to increase from one side safety and security, and from the other side the green around the school, and then the sustainability in its three components: economic, social and environmental.

The paper to answer to the problem identify the exposure using as example, for natural events, the earthquake, but the identical formulation is valid for a large quantity of different events. In the same way is evidenced that risk reduction for car accidents can be obtained using LTZ.

The significance and contribution of this work is to propose a strategy for sustainable mobility as solution to common problem of safety and green near school improving, in the same time, the other components of sustainability. It can be noted that usually LTZ is used in downtown areas to organize traffic flows in commercial zones. 
In the national and international context, there is no organic plan that makes a contribution in the field of schools; for this reason, this paper constitutes an important document, even more in an emergency situation such as COVID-19 in which a certain social distancing is required and a differentiate access to school is obligatory with necessary new areas.

The program was activated before the emergency period, only considering the ordinary problems of green and safety, but today it assumes a significant importance above all because there is no rule that regulates the issue in schools and to suggest a re-reading of the mobility around the schools for the competent authorities.

It needs to emphasize an important basic consideration: in the sector of last mile to the schools there are no documents that provide indications to the school managers, although today it is a delicate topic, just considering the number of accidents in front of the schools and the amount of $\mathrm{CO}_{2}$ emitted in the school areas.

The pandemic issue and the social distancing required reemphasizes the importance of an instrument that provides indications in the school context.

\section{SUSTAINABILITY STRATEGIES}

\subsection{Regional transportation plan}

The RTP was approved in 2016 with a positive environmental assessment by regional department [8]. The EU Commission evaluated the RTP positively.

RTP defines a general vision to orient medium and longterm policies in transport and logistics system. This vision is declined by four goals:

- regional economic development;

- external accessibility;

- internal accessibility;

- sustainability.

The vision is pursued by 10 strategic objectives. To the objectives correspond 10 strategic actions and to the strategic actions correspond 100 operational measures, 10 for each action. (Figure 2).

In particular, the Objective 2 Urban areas directs Action 2 Measures for infrastructure upgrading and services in urban areas, which defines Measure 2.4 Individual non-motorized transport and controlled areas. This measure establishes that it is necessary:

Develop integrated actions for the activation and expansion of pedestrian areas, limited traffic areas (demand control), zones 30 (supply control), green zones (Action Plan on Urban Mobility) and low emissions zones (Sustainable Urban Transport Plans), to promote environmental and social regeneration of the road, especially in urban areas. Support and protect non-motorized modes, and therefore feet and bicycle:

- for the foot mode different degrees of protection must be identified, with specific attention to the areas near the school buildings; in urban areas, pedestrian networks must be built without interruptions, caused by cars and buses, increasing safety and attractiveness.

Actions similar to the pedestrian [24] are indicated for bike mode [25], to identify different cycle infrastructures and to encourage the use of the bike, and for foot and bike way, to realize integrated itineraries directly with the collective transport to improve user safety.

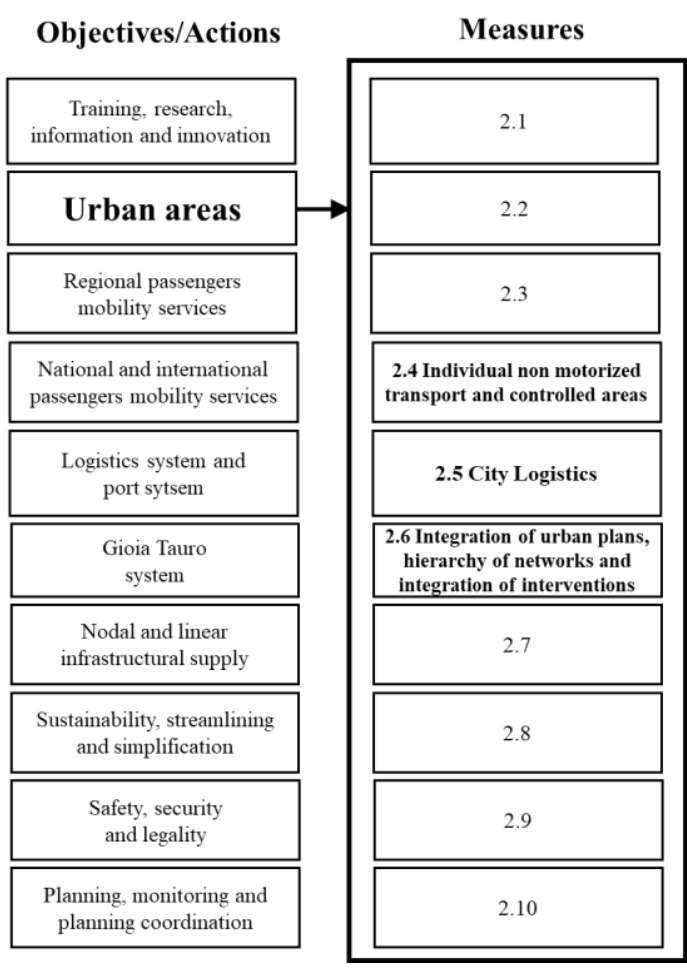

Figure 2. RTP framework

Action 2 also defines Measure 2.5 City logistics and Measure 2.6 Measures for integration of urban plans, for the hierarchy of networks and the integration of interventions. In the hierarchy, the pedestrian network is placed in the first position, followed by cycle network, public transport and, as last, the private transport network, overturning the classical hierarchy.

The Measure 2.5 indicates the interventions for urban logistics to Achieve essentially CO2-free city logistics in major urban centres by 2030 [14]. City logistics [26, 27] is to against climate change and to increase environmental [28-30], economic [31-33] and social sustainability [34-37].

City logistics measures can be summarized on: regulation of the supply, demand management, infrastructural interventions, ICT and ITS applications, Use of eco-friendly and innovative vehicles, interventions for public-private collaboration and reverse logistics $[38,39]$. The Region has carried out an overall technical and administrative way for City Logistics measures by definition and implementation of the planning, programming and implementation processes, and by public engagement $[40,41]$. The aim is to push local administrations to implement effective urban logistics according to the indications of APUM [42, 43] and SUMPs [44-47] too.

After Implementation Program approval [11], two financing calls are published [48]. Cities with more than 30,000 inhabitants, or less but with operational LTZ for cars and significant traffic flows as for tourism, are the beneficiaries. Constraints of the projects are time windows differentiated by type of vehicle: Load, engine, environmental performance. Suggestions for the projects are: ICT/ITS, fleets eco-friendly and innovative and also Urban Distribution Center and Nearby Delivery Area.

The Region provided a supporting decisive role to decision makers at city level. It must be noted that the decision at city level can be assumed only by the city government. The Region government can assume a role of a moral suasion, without 
prescriptive decisions. The city strategies go ahead along three interconnected processes: City planning theories, city rules and city development, which are connected by a circular stage in the goal of smart city [10]. Calabria Region supported city in the first step where the city planning theory is pushed into city rules to address city development. This way is accompanied by public engagement to participate and share the decisions for the transport system.

Regarding the Measure 2.4 for the foot mode different degrees of protection must be identified, with specific attention to the areas near the school buildings, the specific indications was finalized to Green and Safety School program. This program has a first definition with the introduction of a special LTZ finalized to scholar and parents, just outside the physical borders of school buildings.

\subsection{Scuola Sicura program}

Scuola Sicura is the program developed by Calabria Region to give a great impact on sustainable development, in line with higher level policies to school buildings [12] defined in the School Plan. Through the program, the process to safety and environmental certifications has increase in speed for public buildings and schools.

Calabria is characterized by a high seismic risk. About $50 \%$ of the Italian school buildings in zone risk 1 (high risk of earthquakes) are located in Calabria; the other schools are in zone risk 2.

In Italy, school seismic safety is a central problem of the State in view of the fact that there are 19,000 schools in zones 1 and 2.

In recent years the Region has placed its strategy in order to have earthquake-resistant schools: seismic adjustment or demolition and reconstruction and not just "light" improvement.

Scuola Sicura allows to carry out seismic adjustment interventions. About 650 interventions have been launched in schools (some in progress, others completed). A further 150 interventions are to be carried out whose resources have already been assigned.

Calabria is the leader of the Italian regions by number of interventions planned and carried out in schools.

Scuola Sicura goes toward reduction of impacts on social, economic and environmental sustainability [49, 50], which have been estimated for Calabria and reported in literature [12].

Among the social and economic impacts, there is the risk reduction.

Risk depend: on the probability of occurrence of an event; on the vulnerability or on the probability of an element of the system to resist to the event; on the exposure or on the probability of people and goods to stay in the system during the effect of earthquake [51]. [52]:

The risk $\mathrm{R}$ is a typical probabilistic variable depending on

- P probability of occurrence of an event;

- V probability of vulnerability, of an element of the system, to the event, then the incapacity of resistance;

- E probability of exposure of people and goods to stay in the system;

and it has the following formulation:

$$
R=P \cdot V \cdot E
$$

In order to reduce the risk, it is not possible to modify the probability $\mathrm{P}$ of occurrence of an earthquake.

One component that can be modified is the vulnerability $\mathrm{V}$ through scholastic seismic adjustment. In Calabria, there are about 280,000 students who spend most of the day at school where there are also about 32,000 teachers and about 10,000 employees of non-teaching staff. These represent over $16 \%$ of the Calabrian population.

The Scuola Sicura program has the main outcome in the modification of vulnerability $\mathrm{V}$ as defined in the risk Eq. (1). Then, there is a direct relation between earthquake risk and Scuola Sicura. If it uses the apex "bSS" to indicate the vulnerability of school building "before" the intervention with Scuola Sicura, and the apex "aSS" after the intervention, indicating with $\mathrm{h}$ the earthquake, it obtains:

$$
R_{h}^{a S S}=P_{h} \cdot V_{h}^{a S S} \cdot E_{h}<R_{h}^{b S S}=P_{h} \cdot V_{h}^{b S S} \cdot E_{h}
$$

being $V_{h}^{a S S}<V_{h}^{b S S}$

The definition of a free area just outside the school buildings reduce the exposure E creating a large assembly area LTZ. The subsequent fact is the increasing of resilience.

Following the same scheme indicating with the apex "bGS" and "aGS" the condition before and after the intervention of program Green and Safety School by creation of LTZ, it can be write:

$R_{h}^{a S S}=R_{h}^{a S S, b G S}$

being

$R_{h}^{a S S}=P_{h} \cdot V_{h}^{a S S} \cdot E_{h}$

$R_{h}^{a S S, b G S}=P_{h} \cdot V_{h}^{a S S} \cdot E_{h}^{b G S}$

and then obtaining:

$$
R_{h}^{a S S, a G S}=P_{h} \cdot V_{h}^{a S S} E_{h}^{a G S}<R_{h}^{a S S, b G S}
$$

being $E_{h}^{a G S}<E_{h}^{b G S}$

It's evident that for other risk types the exposure can be reduced with the same interventions, as evacuation for security problem.

A classical risk, for which is possible to reduce the occurrence $\mathrm{P}$, is the one linked to safety, for car accident, where are involved pedestrian. For this risk the probability approximates zero in the new LTZ.

In this case the risk equation, indicating with "rs" the road safety, can be write:

$$
R_{r s}^{a G S}=P_{r s}^{a G S} \cdot V \cdot E<R_{r s}^{b G S}=P_{r s}^{b G S} \cdot V \cdot E
$$

being $P_{r s}^{a G S}<P_{r s}^{b G S}$

About the environmental impacts, they are connected to the ITACA protocol which allows to verify the performance of a building with reference to consumption, energy efficiency, environmental impact and user health [49, 50].

RTP measures, described in previous section, are complementary to Scuola Sicura program because they are oriented towards city sustainability. RTP wants to carry out sustainable mobility interventions that also include those to ensure road safety to pedestrians by controlled areas. Scuola Sicura wants to guarantee the sustainability of buildings with interventions to reduce the risk for students, teachers and employees. Then, RTP and Scuola Sicura are oriented to reduce the risk and to guarantee safety outside and inside 
school, and to pursue environmental sustainability [54], in this way constitute a specific background to Green and Safety School, as reported in Figure 3.

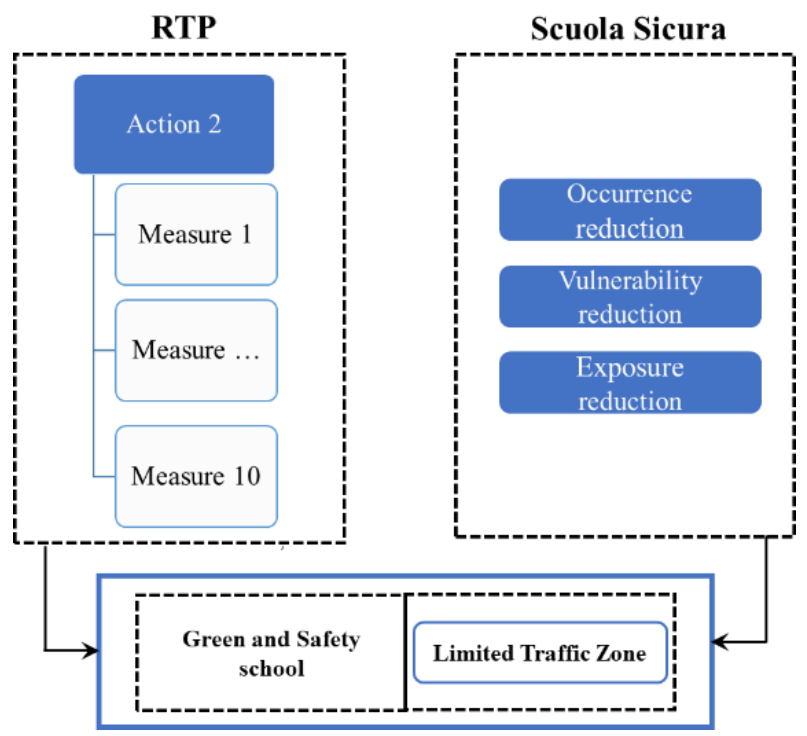

Figure 3. RTP and Scuola Sicura background of Green and Safety School

\section{GREEN AND SAFETY SCHOOL PROGRAM}

\subsection{Methodology}

The Italian Law n. 285 of 28 August 1997 aimed to implement interventions at national, regional and local level to promote rights, quality of life, development, individual fulfillment and the socialization of childhood and adolescence. Article 7 indicates the purposes of the projects [16]:

a) interventions that facilitate the use of time and urban and natural spaces, remove obstacles in mobility, widen the use of environmental, cultural, social and sporting goods and services;

b) measures aimed at promoting the knowledge of the rights of children and adolescents in all citizens, and in particular towards those involved in public utility services;

c) measures to promote the participation of children and adolescents in the life of the local community, including administrative.

The Region indicated policies and measures to be taken: the aim is to increase safety, security and green, then more in general social, economic and environmental sustainability nears schools, where for many hours a day there is a high concentration of pupils, teachers and other school staff.

These policies and measures create traffic-free areas by the closure of the road and the realization of green zone equipped. These, today, are even more significant to guarantee social distancing as a measure to combat the pandemic from COVID19. In fact, the realization of traffic-free areas also allows schools to have more places available to facilitate, for example, the organization of entrance and exit of pupils, or to carry out outdoor activities. For this, which is a common problem in all cities, the proposal of this paper is characterized by portability and universality.

To create traffic-free areas near schools different organizational schemes are possible which also depend on the type of city and its level of urbanization.
In the urban areas of medium size, which in Calabria can be those with a population greater than 10,000 inhabitants, schools are in downtown, where there is high concentration of buildings for offices, shops, and other services. Often the school is in buildings bordering others on one or more sides, so the school is not all surrounded by the street. The organizational schemes might like that in Figure 4, Figure 5 and Figure 6 which show the area before (in the top) and after (in the bottom) the realization of the LTZ.

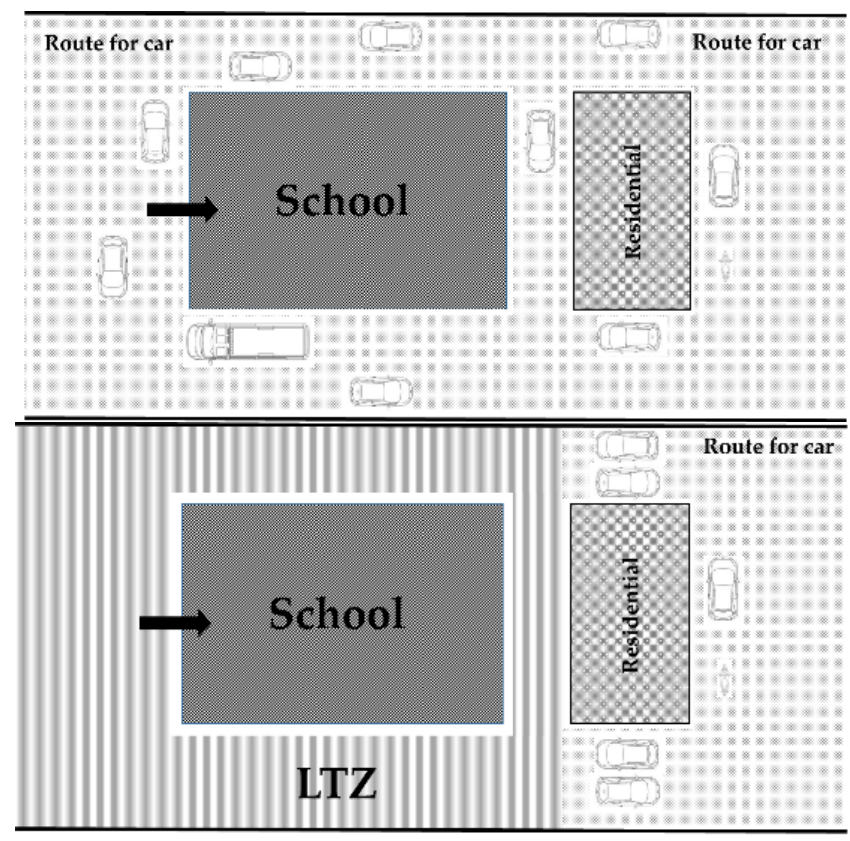

Figure 4. Scheme a

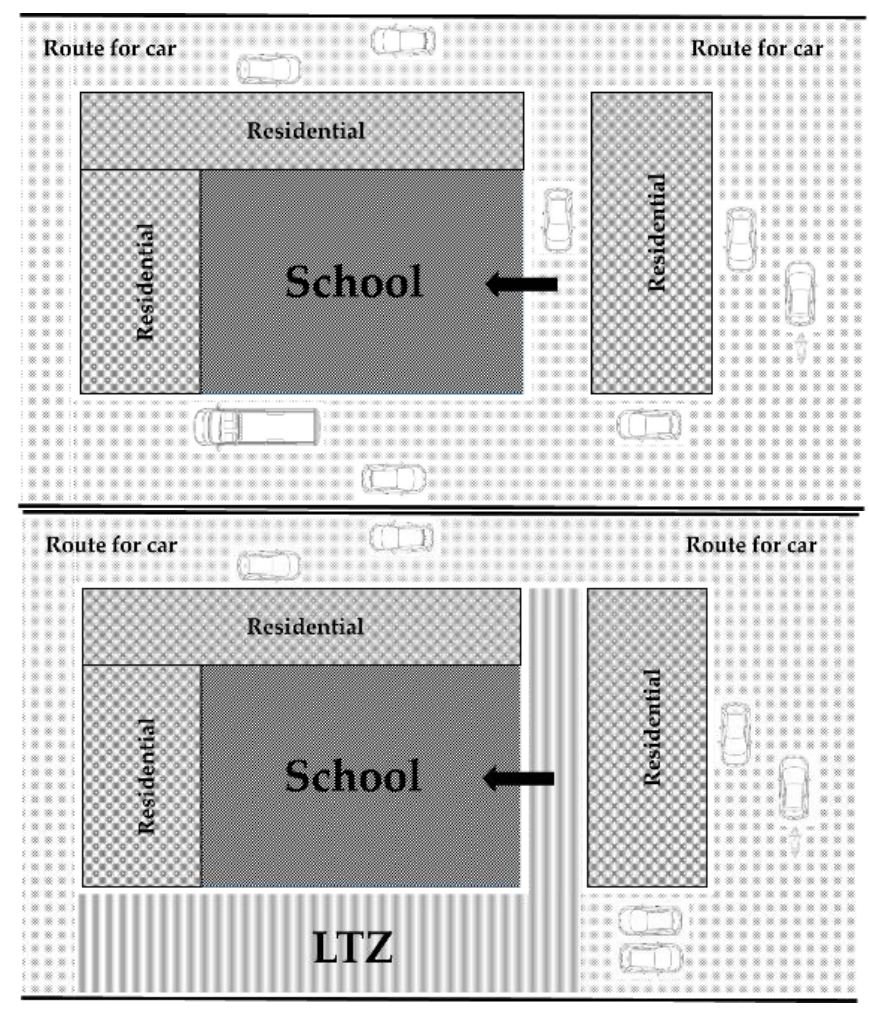

Figure 5. Scheme b

The Region has approved the Implementation Program for Measure 2.4 Individual non-motorized transport and controlled areas of the RTP, in line with Italian law and 
regional strategies for sustainable city development [16].

The program derives from RTP but can be applied just around the school buildings for which seismic adjustment is related to Scuola Sicura program [12].

According to Implementation Program, the Region financed the realization of the LTZ near school. The fundable interventions can be of different typologies, as reported in Figure 7.

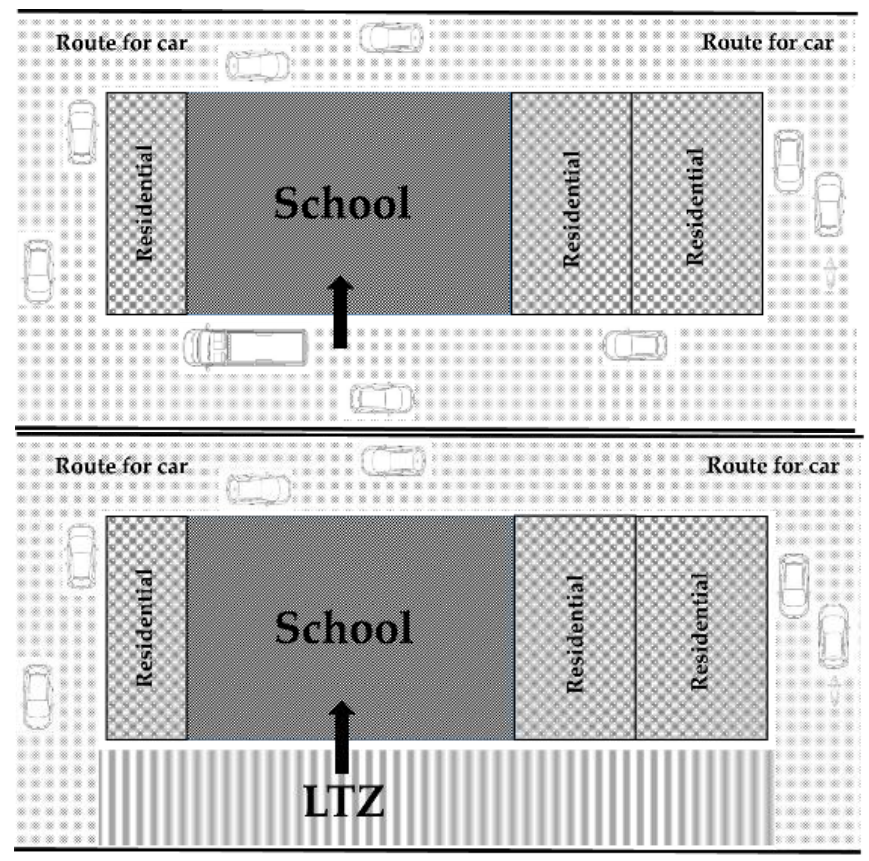

Figure 6. Scheme c

The specifications quantitative and qualitative asked to evaluate each project are:

- reduction of pollution, by size of pedestrian area, average number of students in the last 3 years/day per school, city population, integration and homogenization of several areas of intervention, tourism;

- safe improvement, by consistency and integration of the pedestrian area with safe car plans and emergency/evacuation plans, native plants, equipped areas, ICT/ITS;

- sustainability of the project, by use of recyclable materials with certification, co-financing, governance, participation events, SUMPS preliminary proposal approved, education events on sustainable mobility in the last 5 years.

The cities must to demonstrate that they have participated and shared the proposal with pupils and families involved.

Public participation has been activated in two levels.

In the first level, public engagement, properly specified, aspires to better connect the protagonists of the school, students and their families, teachers, other employees, and local administration, which is the protagonist in the project process to pedestrian area realization around the schools. All the protagonists can design the public engagement according to NCCPE [55] model by several categories of activity:

- lecture/presentation, as writing, performance, workshop, collaboration, citizen research;

- broadcast, as encounter, exhibition, network, consultation, collaborative research;

- event, as websites, exhibit, social media, formal learning, enquiry service.

The Region asks that each Municipality present a specific relation relative to the step made to take the final project decision and the agreement of all actors.

In the second level a public debate between Region and Municipality has been developed.

According to City logistic model of Calabria Region [12] specific training activities have been carried out considering the HSEEP model $[56,57]$. By means of training activities, local administrations were assisted, especially the ones that had a minimal knowledge in LTZ, to obtain projects of high quality.

\begin{tabular}{|c|c|c|}
\hline & Keywords & Description \\
\hline 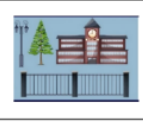 & Safety facilities & $\begin{array}{l}\text { Protective barriers, horizontal and vertical signs, } \\
\text { signs for users with reduced motor and sensory } \\
\text { capabilities to improve the practicability and } \\
\text { orientation in space, roofing, other proposals }\end{array}$ \\
\hline & Infrastructures & $\begin{array}{l}\text { Special pavements for pedestrian, even for users } \\
\text { with reduced motor and sensory capabilities } \\
\text { removal of sidewalks, removal of architectural } \\
\text { barriers, other proposals }\end{array}$ \\
\hline & ICT/ITS & $\begin{array}{l}\text { Video surveillance systems, electronic barriers to } \\
\text { control the area, other proposals }\end{array}$ \\
\hline 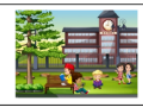 & Urban furniture & $\begin{array}{l}\text { Benches, recycling bins, slides and other } \\
\text { recreational facilities, street lights for low-energy } \\
\text { lighting, photovoltaic systems, other proposals }\end{array}$ \\
\hline & Modal exchange & $\begin{array}{l}\text { Racks equipped also as stations for electric bike } \\
\text { sharing and charging with photovoltaic, parking } \\
\text { other proposals }\end{array}$ \\
\hline
\end{tabular}

Figure 7. Fundable interventions (Illustrations by elaboration from [58])

The first level implied different activities for each project. It can be estimate that more of 100 meetings happened. In the same time, at second level, 2 general meeting (scientific and technical) at regional level have been organized, and more of 30 direct events with participation of technicians of the Region and of the Municipalities.

The aim of two steps is to develop the ideas of pedestrian area not as a top-down decision, but as a bottom-up. The participation ensure the success of the project involving directly family and teachers.

After the approval of the Implementation Program of Measure 2.4, the next step is a call to finance the LTZ around the schools, as traffic-free, green and equipped.

The call is published in December 2019 and it closed in May 2020.

A first important result is obtained: the projects submitted are 25 throughout Calabria [59]. Among these, there are urban areas of medium and small size, localized in the North, Center and South of Calabria.

\section{CONCLUSIONS}

Calabria has addressed own political and technical decisions towards sustainable development, according to international and national target to bring people among the better sustainable development.

For urban areas, these decisions have allowed to quickly start and end the financial process of the Region for some of the RTP measures and to leave projects realization, such as Green and Safety School. 
This program provides for the financing of interventions to realize pedestrian areas around the schools linking international goals and local realization that impacts on real life.

The paper demonstrates how this line can be built.

Green and Safety School is linked to RTP measures for urban areas, because they are finalized to reduce heavy impacts generated by vehicles and to increase sustainability and liveability through controlled zones realization.

Green and Safety School is linked to Scuola Sicura, because both are oriented to green development, to reduce risk and to guarantee safety: the first outside and the second inside school, with a complementary approach to general framework of sustainability strategies of Calabria Region.

The paper highlights how to quantify the risk reduction and then the increasing of sustainability using LTZ around the school. The Eqns. (3) and (4) express the risk modifications, after the reduction obtained by Scuola Sicura expressed by Eq. (2).

In the COVID-19 emergency, the program has an important value because it provides areas available to schools to guarantee social distancing and, in this way, reducing the risk of infection.

\section{ACKNOWLEDGMENT}

Russo, Pellicanò e Trecozzi, from 2016 to 2019, collaborated in the planning process of Calabria Region in different role to prepare RTP and its implementation, as Green and Safety School program.

\section{REFERENCES}

[1] WCED - World Commission on Environment and Development. (1987). Report of the world commission on environment and development: Our common future. sustainabledevelopment.un.org/content/documents/5987 our-common-future.pdf.

[2] United Nations. (2015). Transforming our world: the 2030 agenda for sustainable development. sustainabledevelopment.un.org/content/documents/2125 $2030 \% 20$ Agenda\%20for\%20Sustainable\%20Developm ent $\% 20$ web.pdf.

[3] United Nations. (2015). Global indicator framework for the sustainable development goals and targets of the 2030 agenda for sustainable development. unstats.un.org/sdgs/indicators/Global\%20Indicator\%20 Framework\%20after\%20refinement_Eng.pdf.

[4] United Nations Framework Convention on Climate Change (2015). Paris Agreement. https://unfccc.int/.

[5] European Commission. (2019). Commission staff working document. Country Report Italy 2019. ec.europa.eu/info/sites/info/files/file_import/2019european-semester-country-report-italy_en.pdf.

[6] Italy, MATTM, Ministero dell'Ambiente e della Tutela del Territorio e del Mare. (2017). Strategia Nazionale per lo Sviluppo Sostenibile. www.minambiente.it/sites/default/files/archivio_immag ini/Galletti/Comunicati/snsvs_ottobre2017.pdf.

[7] Regione Calabria (2017). Documento di Economia e Finanza della Regione Calabria (DEFR) per gli anni 2018-2020. Adottato con DCR 277/2017: Nota di aggiornamento del Documento di Economia e Finanza della Regione Calabria (DEFR) per gli anni 2018-2020.

[8] Regione Calabria (2016). Piano Regionale dei Trasporti. portale.regione.calabria.it/website/organizzazione/dipart imento6/subsite/pianoregionale/.

[9] Italy (2020). Geoportale nazionale. http://www.pcn.minambiente.it/mattm/servizi/.

[10] Russo, F., Panuccio, P., Rindone, C. (2014). The process of smart city definition at an EU level. WIT Transactions on Ecology and the Environment, 191: 979-989. https://doi.org/10.2495/SC140832

[11] Calabrò, T., Cozza d'Onofrio, M., Iiritano, G., Trecozzi, M.R. (2019). Regional Plan and Program linked to EU policy for city logistics: The case of Calabria Region. WIT Transactions on The Built Environment, 188: 141152. https://doi.org/10.2495/CC190131

[12] Russo, F., Iiritano, G., Pellicanò, D.S., Petrungaro, G., Zito, C. (2020). Logical framework approach to Calabria sustainable development: the intervention program on school buildings. International Journal of Safety and Security Engineering, 10(2): 235-241. https://doi.org/10.18280/ijsse.100210

[13] Italy (2018). Law n. 2 of 11 January 2018, Order for the development of bicycle mobility and the creation of the national cycling network. http://www.gazzettaufficiale.it/eli/id/2018/01/31/18G00 013/sg.

[14] Russo, F., Calabrò, T., Iiritano, G., Pellicanò, D.S., Petrungaro, G., Trecozzi, M.R. (2020). City logistics between international vision and local knowledge to sustainable development: The regional role on planning and on public engagement. International Journal of Sustainable Development and Planning, 15(5): 619-629. https://doi.org/10.18280/ijsdp.150504

[15] European Commission (2011). White paper 2011. Roadmap to a Single European Transport Area - Towards a competitive and resource efficient transport system. COM (2011) $144 \quad$ final. https://ec.europa.eu/transport/themes/europeanstrategies/white-paper-2011_en

[16] Italy (1997). Law n. 285 of 28 August 1997, Provisions for the promotion of rights and opportunities for childhood and adolescence. https://www.gazzettaufficiale.it/eli/id/1997/09/05/097G $0322 / \mathrm{sg}$

[17] Appolloni L., Corazza M.V, D Alessandro D. (2019). The pleasure of walking: An innovative methodology to assess appropriate walkable performance in urban areas to support transport planning. Sustainability, 11(12): 3467. https://doi.org/10.3390/su11123467

[18] Regione Emilia Romagna. (2019). Camina. www.informafamiglie.it/casalecchio-di-reno/ambientesolidarieta-consumo/altri-progetti/camina.

[19] Emilia Romagna Region (2002). Camina's notebooks 1. Boys and girls make their way. Safe home-school paths and other autonomy paths. La Mandragora Publisher. https://sociale.regione.emiliaromagna.it/documentazione/pubblicazioni/guide/iquaderni-di-camina/bambine-e-bambini-si-fanno-strada

[20] Emilia Romagna Region (2004). Camina's notebooks 6. The city without accidents. Strategies, methods and techniques for designing safe mobility. La Mandragora Publisher. https://sociale.regione.emiliaromagna.it/documentazione/pubblicazioni/guide/i- 
quaderni-di-camina/la-citta-senza-incidenti

[21] Emilia Romagna Region (2004). Camina's notebooks 4. 12 colors for 12 municipalities. Research for the creation of cities that are friendly to children and adolescents in the municipalities of the former health and social area of San Giorgio di Piano. La Mandragora Publisher. https://sociale.regione.emilia-

romagna.it/documentazione/pubblicazioni/guide/iquaderni-di-camina/12-colori-per-12-comuni

[22] Emilia Romagna Region (2007). Camina's notebooks 9. The park I would like. Participatory planning experiences in the municipalities of Albinea, Cadelbosco Sopra and Quattro Castella. La Mandragora Publisher. https://sociale.regione.emilia-

romagna.it/documentazione/pubblicazioni/guide/iquaderni-di-camina/il-parco-che-vorrei

[23] Cittadinanzattiva and Save the Children (2019). Paper for a bill on school safety. www.cittadinanzattiva www.cittadinanzattiva.it/files/primo_piano/scuola/Mani festo_per_una_PROPOSTA_DI_LEGGE_sulla_sicurez za_scolastica_2apr2019.pdf.

[24] Cepolina, E.M., Menichini, F., Gonzales Rojas, P. (2017). Pedestrian level of service: the impact of social groups on pedestrian flow characteristics. International Journal of Sustainable Development and Planning, 12(4): 839848. https://doi.org/10.2495/SDP-V12-N4-839-848

[25] Jiménez, P., Martínez, A., Calatrava, M. (2018). Sustainable urban mobility plan at La Manga del Mar Menor (Spain). Journal of Sustainable Development and Planning, 13(4): 594-604. https://doi.org/10.2495/SDPV13-N4-594-604

[26] Russo, F., Comi, A. (2002). A general multi-step model for urban freight movements. In: Proceedings of the European Transport Conference, vol. 17. Association for European Transport, London.

[27] Rześny-Cieplińska, J., Szmelter-Jarosz, A. (2020). Environmental sustainability in city logistics measures. Energies, $13(6)$ : 1303. https://doi.org/10.3390/en13061303

[28] Waygood, E.O.D., Chatterton, T., Avineri, E. (2013). Comparing and presenting city-level transportation $\mathrm{CO}_{2}$ emissions using GIS. Transportation Research Part D, 24: 127-134. https://doi.org/10.1016/j.trd.2013.06.006

[29] Taniguchi, E. (2014). Concepts of city logistics for sustainable and liveable cities. Procedia - Social and Behavioral Sciences, 151: 310-317. https://doi.org/10.1016/j.sbspro.2014.10.029

[30] Baur, A.H., Thess, M., Kleinschmit, B., Creutzig, F. (2014). Urban climate change mitigation in Europe: looking at and beyond the role of population density. Journal of Urban Planning and Development, 140(1). https://doi.org/10.1061/(ASCE)UP.1943-5444.0000165

[31] Taniguchi, E., van der Heijden, R.E.C.M. (2000). An evaluation methodology for city logistics. Transport Reviews, 20(1):

$65-90$. https://doi.org/10.1080/014416400295347

[32] Browne, M., Allen, J., Alexander, P. (2015). Business improvement districts in urban freight sustainability initiatives: A case study approach. Transportation Research Procedia, 12: 450-460. https://doi.org/10.1016/j.trpro.2016.02.079

[33] Taniguchi, E. (2015). City logistics for sustainable and liveable cities. Green Logistics and Transportation: A Sustainable Supply Chain Perspective; Fahimia, B., Bell,
M.G.H., Hensher, D.A., Sarkis, J. Eds.; Springer International Publishing: Cham, Switzerland, 49-60. https://doi.org/10.1007/978-3-319-17181-4_4

[34] Taniguchi, E., Thompson, R. (2018, eds.). City Logistics 3 - Towards Sustainable and Liveable Cities. Wiley.

[35] Elvik, R., Vaa, T., Erke, A., Sorensen, M. (2009). The Handbook of Road Safety Measures. Emerald Group Publishing: Bingley, UK.

[36] Taniguchi, E., Fwa, T. F., Thompson, R.G. (2013). Urban Transportation and Logistics: Health, Safety, and Security Concerns. Baca Raton, CRC Press.

[37] Russo, F., Comi, A. (2017). From the analysis of European accident data to safety assessment for planning: The role of good vehicles in urban area. European Transport Research Review, 9(1): 9. https://doi.org/10.1007/s12544-017-0225-0

[38] Russo, F., Comi, A. (2020). Investigating the effects of city logistics measures on the economy of the city. Sustainability, 12(4): 1-11. https://doi.org/10.3390/su12041439

[39] Russo F., Comi A (2012). The simulation of shopping trips at urban scale: Attraction macro-model. Procedia Social and Behavioral Sciences, 39: 387-399. https://doi.org/10.1016/j.sbspro.2012.03.116

[40] Calabrò, T., Iiritano, G., Trecozzi, M.R. (2019). Activities training on city logistics: Case of Calabria Region. WIT Transactions on Ecology and the Environment, 238: 161-171. https://doi.org/10.2495/SC190151

[41] Russo, F., Pellicanò, D.S (2019). Planning and sustainable development of urban logistics: From international goals to regional realization. WIT Transactions on Ecology and the Environment, 238: 5972. https://doi.org/10.2495/SC190061

[42] European Commission (2004). Project Cycle Management.

ec.europa.eu/europeaid/multimedia/publications/publica tions/manualstools/t101_en. htm.

[43] European Commission. (2009). Action Plan on urban mobility. COM 490. ec.europa.eu/transport/themes/urban/urban_mobility/act ion_plan_en.

[44] European Commission. (2013). Review of the Action Plan on Urban Mobility. Panteia. Research to progress. ec.europa.eu/transport/sites/transport/files/themes/urban /studies/doc/2013-07-review-of-the-action-plan-onurban-mobility.pdf.

[45] Eltis. (2013). Developing and implementing a sustainable urban mobility plan. www.eltis.org/guidelines/sump-guidelines.

[46] Eltis (2019). Guidelines For developing and implementing a sustainable urban mobility plan second edition. www.eltis.org/sites/default/files/sumpguidelines-2019_mediumres.pdf.

[47] Italy, MIT, Ministero delle Infrastrutture e dei Trasporti, (2017). Individuazione delle linee guida per i piani urbani di mobilità sostenibile, ai sensi dell'articolo 3, comma 7, del decreto legislativo 16 dicembre 2016, n. 257.

www.gazzettaufficiale.it/eli/id/2017/10/05/17A06675/s g.

[48] Regione Calabria. (2018). Manifestazione di interesse. portale.regione.calabria.it/website/portaltemplates/view/ view_bando.cfm?2279. 
[49] Regione Calabria. (2017). Protocollo ITACA, Regione Calabria, Edifici Pubblici. itaca.calabria.iisbeitalia.org/sites/default/files/Protocollo _ITACA_Reg.Calabria_Ed.Pubblici_2017.pdf.

[50] Petrungaro, G., Corasaniti, B. (2019). Sustainable building program of the Calabria region. First results. Sustainable Built Environment Conference, Scilla, Italy. Proceedings book.

www.sbe19scilla.org/index.php/sbe19-proceedings

[51] Russo, F., Chilà, G. (2009). Safety of users in road evacuation: modelling and DSS for demand. WIT Transactions on Ecology and the Environment, 120: 465474. https://doi.org/10.2495/SDP090431

[52] Russo F., Rindone C. (2010). Evaluation methods for evacuation planning. WIT Transactions on The Built Environment. Urban Transport XVI, 111: 335-343. http://dx.doi.org/10.2495/UT100301

[53] Russo, F., Vitetta, A. (2000). Urban road transportation analysis in emergency conditions: Models and algorithms. Advanced in Transport, 6: 533-542.
[54] Thor, D., Karlsudd, P. (2020). Teaching and fostering an active environmental awareness design, validation and planning for action-oriented environmental education. Sustainability, $\quad 12(8)$ : https://doi.org/10.3390/su12083209

[55] NCCPE. (2013). 3209. www.publicengagement.ac.uk/about-engagement.

[56] FEMA. (2019). National Exercise Program. https://www.fema.gov/national-exercise-program.

[57] Russo, F., Rindone C., Trecozzi M.R. (2012). The role of training in evacuation. WIT Transactions on Information and Communication Technologies, 44: 491-502. http://dx.doi.org/10.2495/RISK120411

[58] Free resources. https://it.freepik.com/home (Last access June 2020).

[59] Regione Calabria (2020). Manifestazione di interesse per la concessione di contributi finalizzati alla realizzazione di Aree in prossimità degli edifici scolastici. Elenco istanze pervenute. https://www.regione.calabria.it/website/portaltemplates/ view/view_bando.cfm?3168. 